\title{
ESPELHOS E IMAGENS: UM LEVANTAMENTO DO REPERTÓRIO SOBRE SEXUALIDADE EXISTENTE NA FEBEM/SP*
}

\section{MIRRORS AND IMAGES: A SURVEY ON THE SEXUALITY REPERTOIRE EXISTING AT FEBEM/SP}

\author{
Rubens de Camargo Festeira Adorno ${ }^{1}$ \\ Ana Lúcia de Castro ${ }^{2}$ \\ Rosane de Lourdes Silva Vianna ${ }^{3}$ \\ Mara de Mello Farias ${ }^{4}$ \\ Selma Lima da Silva ${ }^{5}$
}

ADORNO, R. C. F.; CASTRO, A. L.; VIANNA, R. L. S; FARIA, M. M.; SILVA, S. L. Espelhos e Imagens: Um Levantamento do Repertório Sobre Sexualidade Existente na FEBEM/SP. Rev. Bras. Cresc. Desenv. Hum., São. Paulo, 7 (2), 1997.

Resumo: O tema da sexualidade experimenta grande visibilidade nas sociedades contemporâneas. O advento da AIDS, a liberação sexual promovida pelo movimento de contracultura do final dos anos sessenta e as reivindicações do direito ao prazer e ao corpo colocadas em cena, principalmente, pelo movimento feminista, certamente produziram mudanças, no plano do discurso, introduzindo uma nova coloração à discussão. Contudo, essa mudança perceptível no discurso sobre sexualidade estaria se confirmando no que diz respeito às práticas? Estariam as pessoas, de Pato, lidando melhor com as questões relativas à sexualidade e conhecendo melhor, de fato, o próprio corpo e os caminhos do prazer? Este texto apresenta alguns resultados de pesquisa realizada com jovens que se encontram em regirr.e de privação de liberdade na FEBE2víJSP, sobre o tema AIDS e sexualidade.

Palavras-chave: sexualidade, jovens em privação de liberdade, AIDS.

\section{INTRODUÇÃO}

O que se tem verificado, no plano do discurso, é que a sexualidade passou da condição de "não dito", de tema tabu, para a versão, marcadamente biológica, da "Educação Sexual", entendida como ensino do funcionamento, funções e disfunções do aparelho reprodutivo. Travestido sob a roupagem de "Educação Sexual", o discurso oficial das esco- las e unidades de saúde atenderia, aparentemente, à necessidade de se "falar em sexo" num contexto em que já não é mais possível ignorar o tema. No campo da saúde, percebe-se nitidamente a preocupação com a gravidez precoce e o planejamento familiar, como dois grandes norteadores dos "Programas de Educação Sexual” e, em conseqüência, a redução da sexualidade ao aparelho reprodutor, aparece novamente como tônica.

\footnotetext{
* Esta Pesquisa teve o apoio da Assessoria de Planejamento da Febem, contando com o financiamento do Programa Estadual de Prevenção das DST/AIDS, Secretaria de Saúde do Estado de São Paulo.

1 Prof. Associado do Depto. de Saúde Materno Infantil, da Faculdade de Saúde Pública/USR

2 Mestre em Antropologia, pela Pontifóícia Universidade Católica de São Paulo.

3 Socióloga, Assessoria de Planejamento da FEBEM.

4 Mestre em Saúde Pública, pela Faculdade de Saúde Pública/USP.

5 Mestranda de Saúde Pública, Faculdade de Saúde Pública/USR

End.: Av DrArnaldo, 715, São Paulo-SP, CEP 01246-904. Fone: 3066-7702; 3066-7703.

Este trabalho contou também com a participação de Luis Antonio Barata, bolsista de Iniciação Científica do CNPq.
} 
Como escapar da armadilha do discurso reducionista e biologizante e desenvolver um Programa de Educação Sexual no sentido amplo, levando-se em consideração a plenitude da sexualidade humana? Certamente não há um único modelo aplicável a todas as situações etárias, sociais, institucionais, econômicas ou culturais. A resposta a essa pergunta não pode ser dada de pronto, mas sim, construída a partir do conhecimento aprofundado do grupo que se pretende atingir e das condições sócio-culturais do mesmo. Partindo desse pressuposto, propôs-se a realização de uma Pesquisa com o objetivo de levantar o repertório existente acerca da sexualidade, entre os funcionários e jovens atendidos pela FEBEM/ $\mathrm{SP}$, com vistas à implementação de uma intervenção no sentido de promover Educação Sexual e Prevenção de AIDS.

O título proposto nesse trabalho - "Espelhos e Imagens" - procura refletir a atitude recorrente - detectada nas entrevistas - de se reportar a "outro personagem", a "outro local" ou a "outro tempo", para discorrer a respeito de temas e situações ligadas à sexualidade.

\section{METODOLOGIA}

Foram realizadas entrevistas em grupo, com a preocupação em atingir os diversos setores da FEBEM/SP, ou seja: os complexos do Tatuapé, Internatos, Casas de Convivência e Postos de Liberdade Assistida.

Em cada um desses locais entrevistaramse representantes dos vários escalões da hierarquia institucional, a saber: Diretores, Técnicos, Coordenadores de Turno, Monitores, além dos jovens abrigados e internos de circuito grave e médio. Somente no segmento Liberdade Assistida não se entrevistaram os jovens atendidos.

São conhecidas e compreensíveis as dificuldades existentes para a realização de qualquer trabalho de pesquisa numa Instituição como a FEBEM. Maiores ainda são as dificuldades em se realizar uma pesquisa com um tema tão minado na sociedade como um todo. Assim, o critério para escolha dos locais/unidades onde seriam realizadas as entrevistas foi intencional, como é comum em pesquisas de caráter qualitativo. Portanto, as entrevistas - tanto com os jovens como com os trabalhadores - ocorreram nos locais em que as portas se abriram com menos resistência ou temor.

Osjovens abrigados foram entrevistados em salas de aula, nas dependências da Faculdade de Saúde Pública e foram separados em 4 grupos, por sexo e faixa etária, sendo dois do sexo feminino (12-15 e 16-18 anos) e dois do sexo masculino (12-15/16-18 anos). Os jovens internos, por sua vez, foram entrevistados nas dependências das Unidades em que se encontravam internados, em espaços destinados pela direção, após uma discussão com a equipe de pesquisadores; durante as entrevistas, a pedido dos pesquisadores, os jovens permaneceram sem o acompanhamento do monitor.

As entrevistas foram realizadas com base em um roteiro aberto, gravadas e posteriormente transcritas. Os entrevistados não foram comunicados a respeito do tema da entrevista com antecedência, para não levantar grandes expectativas e/ou respostas já prontas e elaboradas antecipadamente. A diretriz que permeou o trabalho de campo foi a de procurar estabelecer um "diálogo informal" com os grupos entrevistados, buscando-se cercar o tema em pauta, sem ir diretamente ao assunto, como forma de garantir a emergência do mesmo da maneira mais espontânea possível.

De modo geral, as temáticas que constaram do roteiro de entrevistas foram, em relação aos jovens internos e abrigados: organização do cotidiano, lazer existente dentro e fora da instituição, leituras, relação com os monitores, formas de organização interna, namoro, masturbação, expectativas em relação ao sexo oposto, conhecimento a respeito do HIV/AIDS; em relação aos técnicos: rotinas, entraves no dia a dia, questões relativas à sexualidade dos jovens e suas expressões, tratamento dado a essas manifestações, orientações dadas pela instituição; em relação aos monitores e coordenadores de turno: rotinas, perfil do monitor ("carcereiro" x "educador"), percepção da sexualidade dos jovens, tratamento dado a essas questões e orientações da instituição.

\section{TEMÁTICAS}

O material proveniente das entrevistas foi organizado em temáticas que emergirem da leitura do mesmo. As temáticas abordadas foram:

$1^{\circ}$ - Estrutura Institucional: refere-se aos conteúdos pertinentes aos entraves e impasses colocados pela organização e estrutura da Instituição;

$2^{\circ}$ - Sexualidade: agrega os conteúdos que emergiram sobre: quem são os atores, quais as práticas sexuais no interior da Instituição e fora dela, as relações de poder permeadas pela sexualidade, as dúvidas e tabus relativos ao tema, tanto por parte dos jovens, como dos trabalhadores, as relações de gênero, o afeto, o outro;

$3^{\circ}$ - Concepções sobre as crianças e jovens da FEBEM: contempla as opiniões e informações 
referidas pelos funcionários sobre a origem, a classe social, a família e os circuitos sociais dos jovens atendidos; - organização interna dos jovens: refere-se às várias formas de se aglutinarem visando à satisfação de suas necessidades materiais, emocionais, sociais, assim como o estabelecimento de suas leis próprias, seus códigos éticos e morais;

$4^{\circ}$ - Violência e uso de drogas: contempla os conteúdos referentes à violência sofrida, bem como o envolvimento com uso de drogas, tanto no interior da Instituição como fora dela;

$5^{\circ}$ - Orientação: agrega todas as informações referentes à orientação que os profissionais entrevistados deram acerca da questão da sexualidade e prevenção de DST/AIDS; também do acesso à orientação que têm os jovens e empregados através de várias ONGs que circulam pela Instituição intermitentemente;

Além dessas categorias preliminares, destaca-se a dimensão "gênero", como um recorte importante para disposição e interpretação dos dados, considerando-se, inclusive, ter a Instituição uma conotação masculina.

\section{Inventário Temático}

Aqui são colocados alguns conteúdos que apareceram, numa leitura preliminar das entrevistas, que serão objeto de análise posterior.

\section{Estrutura institucional}

Devemos destacar que esses temas apareceram diferentemente na fala de técnicos, de monitores e dos meninos(as)/jovens. Em relação aos monitores, o maior peso foi dado ao que consideraram:

- reduzido número de funcionários com relação ao número de internos;

- trabalho estressante;

- falta de apoio técnico;

- falta de apoio psicológico para funcionários - com problemas de alcoolismo, neurológicos e psiquiátricos;

- alimentação ruim.

Uma outra dimensão da "queixa" dos monitores relacionava-se mais diretamente com a falta de informação/formação, bem como de condições de apoio e retaguarda. Assim, identificou-se:

- falta de informação sobre AIDS - principalmente em relação as formas de transmissão, assim como confusão entre doente de AIDS e portador de HIV positivo;

- assistência médica que não atendia às necessidades;

- falta de estrutura para trabalho diário; - estrutura burocrática que impedia o de- senvolvimento de um trabalho educativo; - direção executiva desconhecia o trabalho da base;

- falta de retaguarda para o atendimento às urgências e emergências (existência de 1 auxiliar de enfermagem para todo Complexo do Tatuapé); relataram uma situação em que a "enfermeira" se recusou a tratar um jovem portador de HIV positivo pela falta de instrumentos bloqueadores de contaminação (luvas), delegando para os internos a assistência ao doente;

- presença de um dito popular na FEBEMSP: "os trabalhadores, ou extravasam pelo sexo, ou pelo álcool";

- presença de funcionários que não aceitavam o trabalho com jovens infratores, só permaneciam na Instituição pela dificuldade de encontrar colocação no mercado de trabalho; louco;

- crença de que quem procura psicólogo é

- assimilação pelos trabalhadores da cultura dos internos em virtude do longo tempo de permanência no trabalho (na verdade eles acabavam ficando internados com os jovens); o modo de falar, andar, trejeitos etc. eram incorporados por eles talvez pela proximidade de seus universos;

- grande número de separações, divórcio e relações entre os próprios trabalhadores; e, entre trabalhadores e jovens;

- distanciamento entre o papel do técnico e o do monitor; o primeiro, centrado em desenvolver um trabalho burocrático, deixando de lado seu papel educativo, o segundo, dedicando-se principalmente ao trabalho de corpo a corpo com o jovem.

Nas entrevistas dos técnicos, os maiores problemas diagnosticados referiram-se a:

- falta de um projeto educativo para a Instituição como um todo. Cada Unidade trabalhava seu próprio projeto;

- quanto à sexualidade, não existia atividades programáticas, apenas algumas experiências pontuais de grupos de interesse interno e externo (instituições de ensino e pesquisa; sistema de saúde, através de profissionais de Unidades de Saúde).

Entre os meninos(as)/jovens, a alimentação surgiu como principal queixa, depois da própria privação de liberdade.

Ainda foi recorrente o tema da relação entre os meninos(as)/jovens e os monitores e diretores de unidades, sendo citados os que "conversam" e os que "agridem".

\section{Sexualidade}

Em relação ao tema observou-se a presença dos seguintes conteúdos: 
- vida sexual ativa antes da internação, precocidade na iniciação (após os 7 anos);

- troca através das relações de poder: "o mais forte oprime o mais fraco";

- presença de "nodos", medos e tabus culturais com relação a sexualidade;

- na relação homossexual, presença de critérios masculinos fortes e femininos frágeis; presença de diferentes categorias de jovens: o "desandão" (práticas homossexuais pontuais, é desprezado, quando descoberto; "mariazinha" é o assumido, que é respeitado por todos, percebe-se uma hierarquização com relação aos ativos e passivos);

- sexo como moeda forte na Instituição: se não há dinheiro, usa-se o sexo para troca de mercadorias;

- falta de referência às relações afetivas;

- valores morais e éticos tradicionais (preservar sempre a família, principalmente a mãe; separação de objetos de uso pessoal de jovens "flagrados" fazendo sexo oral);

- práticas sexuais como masturbação, associadas a valores morais e religiosos, que as relacionam com o aparecimento de doenças; essa prática é privilégio dos homens, as mulheres "não fazem isso..."

- meninas que conseguem ter maior expressão de sua sexualidade;

- cultura "machista" predominante entre os meninos e as meninas;

- violência sexual presente no discurso das meninas: relatam abuso sexual por parte de familiares (pais, avós, padrastos e tios); maus tratos também é referido por parte dos familiares (pai ou mãe, sempre associado ao alcoolismo);

- homossexualismo feminino assumido explicitamente, como opção;

- falta de informação sobre órgão reprodutor, sobre sexualidade de forma geral, sobre concepção e contracepção;

- AIDS vista como doença de homossexual.

\section{Concepções sobre crianças e jovens}

No que se refere a este conteúdo específico observou-se:

- como discurso mais recorrente: jovens "de família"; jovens de "rua";

- jovens de "família" com mais poder pois a família exerce maior controle sobre os atos praticados pela e na Instituição (sofrem menos violência; menos discriminação, etc); referem algo que a família não supre que os leva para a rua;

- jovens de "rua" mais vulneráveis têm que impor seus direitos através da força, contestam mais, "não tem nada a perder", não tem barreiras, são mais atraentes;

- relação entre os novos e velhos tempos: "hoje, a maioria dos internos é reincidente, antigamente não era assim... ", "... a partir do envolvimento crescente com as drogas "pesadas" o perfil do interno mudou, os jovens de classe média acabam chegando...", “... temos mais alfabetizados, discutem até política, antigamente não era assim..."

Observou-se igualmente a seguinte concepção dos jovens do sexo masculino, na visão dos monitores: os mais velhos e os mais novos que mantêm uma relação de força entre si; os de família e os de rua (estes "desandam" os de família); "... aqui dentro, quando o jogo dança, posso entrar na violência" "... lá fora tenho que tomar cuidado senão eu danço"; "... os mais fortes, o mais criminoso não fica aqui...”; “... como controlar essas situações: o mais forte com relação ao mais fraco eu controlo, como fazer para controlar o desejo?"

$\mathrm{Na}$ visão dos jovens encontramos figuras representadas pelo "Jack", que significa o "estuprador", não aceito pelo código de ética e moral deles, assim como o "aí cagüeta"; temos, ainda, o "desandão", o homossexual assumido, que é por eles respeitado.

Verificou-se também que:

- os jovens constroem seu próprio código de moral e ética, por exemplo: regras com relação ao imaginário homossexual "ele faz porque gosta ou quando precisa"; "a mãe é nossa maior advogada", xingá-la é muito grave, namorar na frente dela é desrespeito; "se dois transa entre si como fica os 38" "...veado é só aquele que é comido..." "eu não transo homem, eu sou muito macho..." "....nojo não é uma questão de doença, é questão de higiene" (separam copos, talheres daqueles que foram pegos fazendo sexo oral);

- esses jovens têm um circuito de sociabilidade ainda desconhecido por exemplo, com relação às drogas;

- quanto aos jovens do sexo feminino na visão dos monitores, temos: "as meninas são mais dificeis"; "...elas vêm de um nivel muito baixo"... "elas não se importam com a gravidez elas querem só homem" (elas preferem pular o muro a cuidar do filho); - espera-se das jovens que assumam o papel de mãe, quando se encontram grávidas. Vêm como excludentes seus papéis de mulher ou jovem adolescente.

\section{Uso de drogas e violência}

No que se refere ao uso de drogas e violência registramos os seguintes conteúdos:

- convívio precoce com as drogas: iniciam com cola, esmalte, passando pela maconha, "farinha", drogas injetáveis, "crack"; - aparecimento de drogas na FEBEM, que 
chegam através de visitantes, dos próprios jovens e dos funcionários;

- com relação ao "crack", ele vem para ficar "...é é mais barato, livre acesso, propicia maior 'barato'... 'relação direta entre o aumento do consumo de droga e o crescimento do número de roubo, latrocínio, furto e violência;

- não referem um programa de desintoxicação para atender drogadiços;

- envolvimento com as drogas submetendo a família a riscos levando os jovens a abandonála; sexual;

- uso de droga interferindo na atividade

- uso de psicotrópicos, principalmente gardenal, para amenizar os efeitos da abstinência;

- abordagem em relação às grávidas, somente quanto ao seu papel reprodutor e não quanto à sexualidade;

- desconhecimento quanto as formas de transmissão de HIV/ AIDS;

- falta de capacitação para tratar com jovens HIV positivo, principalmente quanto à comunicação de sua contaminação;

- manifestação do desejo sexual, por parte das meninas, vista como indigna e imoral;

- dificuldade de tratar com a sexualidade da criança. Do adolescente espera-se algum tipo de expressão de sua sexualidade, da criança, nao;

- nas Casas de Convivência, expectativa de que a "comunidade" supra as necessidades dos jovens oferecendo informação adequada sobre sexualidade.

\section{QUESTÕES RELEVANTES ENCONTRADAS A PARTIR DA PESQUISA}

A partir de uma primeira leitura flutuante das entrevistas, levantaram-se algumas questões, com base em temas, conceitos e juízos, emitidos ou descritos, de maneira recorrente, pelos entrevistados.

- não enquadramento nas formas de organização interna (bancas, firmas, jumbo) traz problema de marginalizarão para o jovem;

- existência de castigos como formas de $\mathrm{O}$ Problema da Identidade ou das punição, tanto físicos como aqueles que privam Id en tid ad ex de alguns direitos (direito a visitas, a refeições coletivas e outros).

O Problema da Identidade ou das Identidades

A questão da identidade ou das identidades da clientela da Febem são referidas a partir de dicotomias, oposições, comparações. Nessas comparações, a expressão ser "de família" ou ser um "menino de família" aparece como uma dimensão central, opondo-se a ser de "rua", ou de "família desorganizada" ou de "pais desconhecidos". Essas considerações que atentam para um determinado imaginário, que relaciona discricionaria-mente para uma relação entre "boa família" e "boa conduta", e por outro lado opõe a categoria "ser de rua", ou "da rua" indiscriminadamente, independente de se caracterizar como a imagem tradicional do "menino de rua", mas como um lugar, um espaço no qual se apreende o "ser infrator". Por outro lado, caracterizá-los como jovens "infratores" também apresenta problemas em relação à extensão dessa definição, que se pauta pelo limite de ação tipificada pela lei e que, dessa forma, passa a definir, não apenas o ato infrator mas uma categoria de identidade social.

Poder-se-ia discutir essa questão de uma outra maneira, identificando os círculos de identidade, ou sociabilidade, que se reportam a um plano coletivo, e não a um problema de comportamento individual que passa a ser descrito como um "mal de origem", ou como uma categoria "legal". Vale nessa direção citar que se deve, no plano coletivo, que considera o comportamento como uma dimensão das formas de sociabilidade, dizer que se trata de "comportamentos", "histórias", "identidades".

Do ponto de vista da "saúde pública" mais importante é conhecer as distintas trajetórias que colocam o menino/jovem em situação de vulnerabilidade social.

\section{A Transitoriedade}

Uma outra categoria que pode apoiar a análise é a de transitoriedade: essa refere-se tanto aos "jovens" que consideram estar na instituição como uma situação de passagem, uma situação transitória, como em relação aos funcionários que transitam de uma unidade a outra, ou de um setor para outro. Os jovens ainda são alvo de transferências, seja por determinação judicial, seja por conveniência, por facilitar a resolução de problemas do corpo funcional.

Em relação a utilizar a transitoriedade como um conceito analítico, há que também considerar aspectos da sociedade contemporânea, e sua relação com o tempo, o consumo, a efemeridade, a fragmentação.

Essa recorrência à transitoriedade impõe de e, ao mesmo tempo, justifica a inexistência de um plano, de um trabalho mais efetivo em relação à permanência do menino/jovem dentro da instituição.

Todas as referências a diálogos, dúvidas perguntas, conversas são eventuais, cotidianas, passageiras, não há uma continuidade ou um pla-

-75 _no de ação atrás desses diálogos entre monitores e internos. 
Por outro lado, qualquer envolvimento, planejamento, ou continuidade implica em um trabalho, que é sempre justificado como inútil em fiança dessa mesma transitoriedade ou do caráter da identidade imutável do menino/jovem que tem o pé na rua.

\section{As Normas, o Sistema, a Responsabilidade}

As nomas, as ações, as interdições são construídas a partir dos arranjos locais, do tipo de direção e da "experiência" dos funcionários que trabalham diretamence com os meninos/jovens.

A justificava das ações dá-se sempre em função de uma idéia de "arbitragem" entre os mais "fortes" e os mais "fracos" organização de bancas, firmas, "mais bandidos" e "laranjas" meninos "de família" e meninos "de rua"; essa arbitragem está presente também e, principalmente, em relação aos exercícios que envolvem a sexualidade.

Afinna-se, para tal o uso ou a capacidade de empreender um "jogo" que, em situações limites, apelam para a violência e coação física.

Há no discurso das entrevistas uma relativização de normas ou de preceitos legais, como, por exemplo, em relação ao ato sexual, que pode ser relativizado ou considerado belicoso. O que não se faz é trábalhar essa questão como um fato a ser encarado de frente.

Essa relativização, aliada à justificativa de trasitoriedade e a construção de um rótulo de iden- tidades justificam o não responsabilizar-se por uma ação educativa preventiva ou de reabilitação.

\section{O Código Ético Moral}

Entre os meninos/jovens observa-se a construção de um código de ações e de interdições, que dizem respeito tanto a comportamentos intentos, como em relação a comportamento, ações em geral. Esse código tem um caráter hegemônico, mas não exclusivo, principalmente em relação aos comportamentos mais gerais. Esse código é tomado como absoluto ou natural. Entretanto, essa condição é permeada no discurso, através da referência "depende" como uma condição a ser considerada ou refletida, ou desejada a partir da história, ou do desenrolar de cada situação. Essa referência a uma relativização, que aparece marginal a um discurso, quer seja ele autoritário, ou de conteúdo machista, traduz uma possibilidade de interferência.

Uma estratégia possível para o trabalho com jovens privados de liberdade seria buscar entrar no vocabulário dos jovens, não para fazer coro com ele, mas para desvendá-lo, discuti-lo, relativizá-lo, o que poderia indicar caminhos para tratar de assuntos que são considerados tabus, deste modo assimilando o discurso sobre sexualidade às práticas e possibilitando um maior conhecimento do próprio corpo, dos caminhos do prazer e das questões de promoção da saúde a eles associados.

Abstract: The subject of sexuality experiences great visibiiity in contemporary societes. The advent of AIDS, the sexuai iiberation promoted by the countercuiture movement of lhe sixties, as weii as the ciaims towards the rights to pieasure and to the body, piaced mainiy by the feminist movement, certainly promoted changes on lhe discourse levei, introducing a new colouring to the debate. Nevertheless, a question still remains: would this perceptible change on the sexuaiity discourse levei be confirming itself on the sexuai practices levei? Wouid peopie be realiy dealing better with questions related to sexuaiity and be better knowing their own body and the paths to pleasure? This article presents sorne results of a piece of research carried out with youths deprived of freedom at FEBEM/SP, on the theme AIDS and sexuality.

Key-words: sexuaiity, youths deprived of freedom, AIDS.

\section{REFERÊNCIAS BIBLIOGRÁFICAS}

1. GIDDENS, A. A transformação da intimidade: sexualidade, amor e erotismo na sociedade moderna. São Paulo, UNESP, 1993.

2. HABERMAS, J. A unidade da razão na muitiplicidade de suas vozes, Rev. Bras. de Filosofia, 4: 58-86, 1989.
3. LOYOLA, M.A. (org.) AIDS e sexualidade: o ponto de vista das ciencias humanas Rio de Janeiro, Relume-Dumar i, 1994.

4. PARKER, R. A construção da solidariedade: AIDS, sexualidade e política. Rio de Janeiro, RelumeDumará/IMS/UERJ, 1994. 